\title{
A composiç̃o de um questionário sobre o léxico do gado
}

\author{
Vanderci de Andrade AGUILERA \\ Maria Beatriz Tozetti FIGUEIREDO \\ Universidade Estadual de Londrina
}

Resumo: Os dialetólogos e lexicógrafos reconhecem a dificuldade de se elaborarem os instrumentos de coleta de dados dialetais e lexicais devido à escassez de subsídios para a sua composição. Neste artigo discutimos as etapas da constituição de um Questionário voltado para a pesquisa do léxico do gado.

\begin{abstract}
Dialectologists and lexicographers recognize the difficulties in the elaboration of instruments for collecting dialectal and lexical data due to the lack of subsidy for its composition. In this article we discuss the stages in the constitution of a questionnaire for research of cattle lexical items."
\end{abstract}

Resumen: Los dialectólogos y lexicógrafos reconocen la dificultad de elaborarse los instrumentos de coleta de datos dialectales y lexicais debido à la escasez de subsidios para su composición. En este articulo discutimos las etapas de la constitución de uno Cuestionario volvido à la pesquisa del léxico del ganado.

\section{Introdução}

$\mathrm{Na}$ realização de estudos dialetológicos, geolingüísticos e, mais recentemente, sociolingüísticos, freqüentemente adotam-se questionários estruturados como instrumento de coleta de dados, dada a eficácia desse procedimento metodológico. De acordo com Tarallo (1999, p. 22),

SIGNUM: Estud. Ling., Londrina, n. 5, p. 9-47, dez. 2002 9 
esses módulos têm por objetivo homogeneizar os dados de vários informantes para posterior comparação, controlar os tópicos de conversação, e, em especial, provocar narrativas de experiência pessoal.

A utilização desse recurso mantém, pois, assegurado o caráter científico necessário à pesquisa e ainda torna menos complexa a obtenção do registro dos fenômenos lingüísticos que se pretende estudar.

No entanto, ainda que eficaz e amplamente empregado, pouco se tem discutido a respeito da composição desse tipo de roteiro para entrevistas. O questionário, com freqüência, figura apenas como um dos anexos das pesquisas, como se não fosse o resultado de uma árdua tarefa de investigação não só teórica mas também sócio-lingüística-cultural, resultante do processo de integração do pesquisador na comunidade eleita para o estudo.

Pretende-se, neste espaço, apresentar o questionário elaborado para coleta das unidades lexicais referentes ao gado no município de Camapuã, Mato Grosso do Sul, bem como as etapas seguidas na elaboração desse instrumento, oferecendo, assim, informações que poderão ser úteis a outros pesquisadores.

\section{A Validade do Instrumento}

A coleta de dados através de entrevistas, sobretudo quando adotado um questionário estruturado, pode ser considerada, como de fato observam alguns autores, um instrumento artificial o suficiente para comprometer a fidedignidade das informações obtidas. $\mathrm{Na}$ verdade, não se pode ignorar que a realização dessas entrevistas constitui um evento com características singulares. Entre esses aspectos pode-se mencionar: i) é o pesquisador quem busca o informante; ii) o entrevistador é quem seleciona os tópicos, dirigindo a conversa; e, iii) ainda, todas as informações são registradas. Pouco resta de iniciativa ao informante, pois quase tudo é determinado pelo pesquisador. 
Entretanto, não se pode afirmar que situações de entrevistas, que envolvem essas mesmas características, sejam circunstâncias raras na vida dos entrevistados. Bortoni-Ricardo (1984, p. 11), abordando o fato de que alguns estudiosos consideram as entrevistas um método ineficaz e que outros a recomendam, mas não sem algumas ressalvas, postula:

Ambas as posições partem do pressuposto de que as entrevistas são acontecimentos raros e insólitos na vida das pessoas. [...] Quero argumentar, contrariamente, que eventos de fala muito semelhantes à entrevista sociolingüística ocorrem com bastante freqüência no cotidiano dos migrantes entrevistados, como, por exemplo, numa consulta médica, no cadastramento na Secretaria de Serviços Sociais ou em órgãos do Ministério do Trabalho ou da Previdência Social, por ocasião da matrícula dos filhos na escola, num interrogatório na polícia ou no tribunal, etc.

Além desses argumentos a favor da entrevista, a menção de outros trabalhos, alguns recentes e outros de décadas atrás, servem para evidenciar o fato de que os questionários encontram-se, há muito, incorporados à metodologia da pesquisa lingüística, demostrando, através de diferentes estudos, a sua validade.

Entre os primeiros trabalhos, versando sobre o português do Brasil, a utilizar o questionário lingǘstico para a coleta de dados encontra-se o Questionário Lingüistico-Etnográfico Brasileiro (Rector, 1983, p. 1), elaborado por Cândido Jucá Filho, com a finalidade de compor o Atlas LingïísticoEtnográfico do Brasil. Essa pesquisa foi proposta por Celso Ferreira da Cunha e Serafim da Silva Neto, em 1957, em Lisboa, por ocasião do Colóquio Internacional de Estudos Luso-Brasileiros. O referido questionário, através do tempo, tem servido de base ora para estudos geolingüísticos voltados para a elaboração de atlas lingüísticos das diferentes regiões do país, ora para estudos léxicos das diversas atividades humanas, como a pesca, a agricultura, a indústria caseira e/ou artesanal, a náutica, entre outras, demonstrando tratar-se de um recurso seguro e indispensável. 
São inúmeros os estudos que têm como base a aplicação de questionários estruturados. Um deles, com o objetivo de registrar aspectos fonológicos, foi realizado por Fischer (1974, p. 88). Em seu artigo Influências Sociais na Escolha da Variante Lingüistica, esclarece que, entre outros instrumentos para a coleta de dados, utilizou "um questionário formal aplicado apenas às crianças mais velhas".

Os estudos de cunho léxico são os que mais exigem a utilização de questionários estruturados pela necessidade de homogeneizar os resultados, que só se obtém mediante a elaboração e aplicação de questionário com formulações claras, bem definidas, que não deixem margem à dupla interpretação quanto ao(s) nome(s) dos referentes investigados.

Recentemente, na UEL, duas dissertações de mestrado foram direcionadas para a elaboração de glossários de atividades especiais: a de Castro (2001, p. 12) e a de Lambach (2002). A primeira autora procedeu à pesquisa do vocabulário da cultura do café em Londrina e no capítulo sobre os aspectos metodológicos, observa que é

necessário destacar que as entrevistas realizadas com produtores e colhedores de café foram feitas através de questionário elaborado a partir do questionário usado para o estudo léxico do café na terceira idade (trabalho anterior da autora).

Da mesma forma, Lambach (2002, p. 7), no estudo sobre o léxico da cachaça, em Morretes, comenta

[...] optou-se pela pesquisa de campo a fim de recolher in loco dados de natureza oral. Considerando essa natureza, fez-se uso do método direto, na modalidade inquérito.

O questionário tem servido não só a trabalhos que privilegiam os aspectos fonológicos e lexicais, mas também a pesquisas que têm por 
objetivo registrar o uso sintático de diferentes elementos da língua. Há, para efeito de exemplificação, a pesquisa de Duarte (1989, p. 19) que, em seu artigo Clítico Acusativo, Pronome Lexical e Categoria Vazia no Português no Brasil, afirma: "O corpus utilizado para a análise provém de gravações da fala natural, obtidas através de entrevistas com 50 paulistanos nativos, e da linguagem da televisão".

Data da mesma época, ainda, o trabalho de Oliveira (1989) que, estudando o preenchimento, a supressão e a ordem do sujeito e do objeto em sentenças do português do Brasil, faz a seguinte observação: "Do modelo de Labov (1974, p. 52), utilizaram-se o conceito de fato lingüístico, o método de entrevista, [...]." Em outro parágrafo, descrevendo o corpus, a autora cita novamente o questionário como instrumento de coleta de dados: "Esses sujeitos foram responsáveis por 60 textos escritos e 60 entrevistas orais [...]".

Finalmente, considerando o trabalho de Baernert-Fuerst (1989, p. 220), que aborda a sociolingüística qualitativa e quantitativa no que concerne aos seus aspectos metodológicos, também é possível verificar o uso do inquérito. Referindo-se ao seu próprio estudo, o autor esclarece: "Nele foram aplicadas duas técnicas de levantamento de dados: a observação participante e a entrevista sociolingüística [...]"

Assim, dirimindo as dúvidas quanto à eficácia do questionário como instrumento de coleta de dados nas pesquisas de cunho lingüístico, passase a discutir a sua elaboração.

\section{Etapas da Composição de um Questionário Lingüístico}

Ao iniciar esta seção, faz-se necessário esclarecer que as abordagens que se seguem dizem respeito, sobretudo, a questionários para investigação lexical, embora as observações também sejam úteis aos de outra natureza.

Para a coleta de dados lexicais sobre o gado no município de Camapuã, no entanto, foi necessário começar praticamente do ponto zero, 
visto não se ter conhecido um modelo precedente. A colaboração única constituiu-se de 80 questões, compostas por Aguilera e Mortoza (2002) para investigar o léxico do gado na região de Quirinópolis (GO).

A princípio, deve-se considerar que a composição de um questionário lingüístico pressupõe três principais etapas. A primeira refere-se à investigação dos aspectos sócio-econômicos e culturais da comunidadealvo do estudo. A segunda trata da composição de campos semânticos dos quais serão originadas as questões. Por último, está a composição do questionário propriamente dita, que envolve a elaboração das questões, a testagem e a reelaboração das perguntas como forma de readequação aos propósitos da pesquisa.

A etapa inicial para a construção do questionário lingüístico diz respeito ao conhecimento do grupo social, alvo do estudo. Esse conhecimento pode se dar de duas maneiras distintas, mas não excludentes: pela inserção do pesquisador na comunidade ou através de pesquisa bibliográfica. Esta última poderá ser dispensada se o investigador for parte integrante do grupo, inserido na atividade em estudo, ou que esteja ligado a um indivíduo que o represente, de forma tal que seja possível o acesso a todos os dados necessários. Diferentemente, as informações obtidas através de publicações dificilmente se mostrarão suficientes a ponto de dispensar o contato direto com a comunidade. Por exemplo, para a realização de seu trabalho, Lambach (2002, p. 7) relata ter buscado as informações necessárias à composição do seu questionário de ambas as formas:

A constituição da amostra de informantes e a elaboração do questionário lingüístico foram antecedidas por uma viagem a Morretes. [...] Concomitante aos primeiros procedimentos, foi realizada uma pesquisa bibliográfica sobre a região em que se realizaria a pesquisa de campo e sobre o tema da dissertação.

Ainda observando a necessidade da interação com trabalhadores na atividade da pecuária, na busca dos dados indispensáveis à pesquisa, 
convém observar que a colaboração de um indivíduo ligado ao grupo estudado, que não se constitua em informante, pode facilitar sobremodo a composição do questionário lingüístico. No caso do campo léxico do gado, a elaboração do questionário partiu do conhecimento adquirido devido à inserção de uma das pesquisadoras na comunidade, que ainda contou com a colaboração de um profissional ligado à criação do gado vacum, o que favoreceu a constante readequação das questões.

A segunda etapa do processo de elaboração do inquérito consiste na sistematização dos campos semânticos, necessária para a coleta dos itens lexicais que se pretende registrar. A elaboração de questões por meio dos campos semânticos carrega duas grandes vantagens: uma é a de facilitar a concentração das idéias do informante em uma área do conhecimento de cada vez, pois as unidades lexicais encontram-se de alguma forma interligadas; e a outra diz respeito ao trabalho do próprio pesquisador que poderá ir se aprofundando cada vez mais pelo detalhamento de cada etapa da atividade.

Esse procedimento não constitui uma novidade. Silva Neto (1986, p. 194), já em 1950, apresenta uma divisão por campos semânticos ao abordar a construção de um questionário para a coleta de dados dos falares modernos e, em seguida, afirma que "com esse planejamento preliminar, é muito mais proveitoso o estudo dos falares, e os resultados serão mais dignos de confiança."

Rector (1983, p. 15), também, analisando o aspecto metodológico do questionário de Antenor Nascentes, igualmente refere-se à importância da divisão por campos semânticos:

A questão talvez se localize no fato de não haver uma estruturação léxica a nível de campos semânticos. Em um trecho anterior, lê-se: Com referência ao conteúdo, as perguntas devem estar relacionadas com esferas semânticas.

SIGNUM: Estud. Ling., Londrina, n. 5, p. 9-47, dez. 2002 
Esse mesmo recurso foi utilizado por Lambach (2002, p. 9): “As perguntas do inquérito, em número de 116, foram, distribuídas em oito subáreas, buscando-se contemplar as diferentes fases do processo do fabrico da cachaça."

Dessa forma, considerando a relevância da divisão por campos semânticos, após a obtenção das informações necessárias, passou-se à tarefa de determinar os núcleos que seriam abordados na pesquisa sobre o léxico do gado e que foram assim delimitados: a) partes do corpo; b) cortes de carne e pratos feitos com carne bovina; c) parasitas, doenças, intervenções cirúrgicas e medicações; d) faixas etárias e procriação; e) alimentação; f) raças, cores e outras características físicas; g) transporte; h) comércio; i) trabalhadores, animais e tarefas; j) vestuário; l) divisões da propriedade rural e madeiras utilizadas nessas divisões; $m$ ) instrumentos e n) comportamentos e atitudes do gado bovino. A divisão por campo semântico resultou, assim, em um roteiro eficiente para a posterior composição do questionário.

A terceira etapa diz respeito à elaboração e à reelaboração das questões, com a finalidade de remover, assim, imperfeições que poderiam influir no resultado do estudo. Mais uma vez, faz-se necessário ressaltar que também nesse momento será de grande valia a contribuição de algum representante do grupo social pesquisado, a fim de que se proceda à avaliação do instrumento de coleta de dados. O questionário passa, dessa maneira, por um crivo, sendo testado e aprimorado através de pequenos ajustes ou, até mesmo, com a inclusão e exclusão de perguntas.

A necessidade desse refazer também já foi abordado por Silva Neto (1986, p. 193): "É preciso, em primeiro lugar, organizar um questionário, que pode ser, depois das primeiras experiências, ampliado e acrescido." Também Castro (2000, p. 12) menciona que, para a versão definitiva de seu questionário sobre a cultura do café, partiu de outro inquérito já existente, aperfeiçoando-o, contando, também, com a colaboração de um profissional da comunidade, ligado à cafeicultura: 
É necessário destacar que as entrevistas [...] foram feitas através de questionário [...] elaborado a partir do questionário usado para o estudo léxico do café na terceira idade, [...] com a ajuda de um produtor e comerciante de café que acrescentou perguntas relevantes ao questionário.

O questionário do ALiB constitui outro exemplo, este bastante recente, da necessidade de revisão e de reelaboração. A esse respeito, Altino (2001, p. 26) comenta:

O trabalho de aprimoramento desses questionários vem sendo feito por vários estudiosos em todo o Brasil, passando por reformulações que, discutidas em dois eventos científicos do ALIB e nas reuniões do Comitê Nacional, deram origem às versões de 1998 e de 2000.

A composição do questionário do $\mathrm{ALiB}$ apresenta-se especialmente complexa devido às diversas áreas geográficas e, conseqüentemente, às diferentes culturas que pretende abranger, ao ser aplicado em todos os Estados do Brasil. Faz-se necessário considerar, ainda, que a reformulação do questionário transcende a fase anterior à sua aplicação visto que algumas distorções serão evidenciadas apenas no momento da entrevista. Sobre isso, Silva Neto (1957, p. 30) postula: "O questionário tem de ser organizado com antecedência, mas na verdade só a pesquisa no campo mostra o que se pode e o que se deve perguntar."

Não há dúvida de que a elaboração de um questionário dialetológico (lexical ou não) se tornará mais simples e rápida com o apoio de outros questionários sobre temas similares que possam ser tomados como base. Para a coleta dos dados lexicais sobre o gado no município de Camapuã (MS), no entanto, foi necessária a elaboração do questionário, visto não se ter tido acesso a algum modelo precedente. A colaboração única, conforme se explicitou, constituiu-se de 80 questões, compostas por Aguilera e Sandra Mortoza (2002), com a finalidade de investigar o léxico do gado na região de Quirinópolis (GO). 
Assim, considerando as dificuldades inerentes à composição, ressaltase que foram necessárias inúmeras retomadas do questionário sobre o léxico do gado a fim de procurar esgotar todas as abordagens possíveis e de se corrigir as distorções que fossem detectadas. As perguntas foram, portanto, elaboradas e reelaboradas sendo, seguidamente, submetidas à avaliação do profissional colaborador.

Dessa forma, o instrumento final passou a contar com 206 questões, de 4 diferentes classes: perguntas indiretas ou descritivas, que previam uma única resposta conceitual, como se pode exemplificar com a Questão 196: Como se chama aquele instrumento feito de chifre, comprido, em que se assopra e serve para chamar o gado?; perguntas diretas, com resposta enumerativa, como: O que o gado come?; perguntas cuja resposta constitui uma narração ou descrição, como no exemplo: Como se prepara o churrasco?; e, ainda, perguntas com relatos de experiências pessoais, tais como: O senhor conhece alguma história triste que aconteceu com algum boiadeiro da região?. Dessa forma, dada a importância desse processo constituinte do inquérito, passa-se, a seguir, à descrição detalhada, por campo semântico, das dificuldades encontradas em determinadas questões e como essas foram sanadas.

As questões relacionadas às partes do bovino compreenderam órgãos internos e externos, as secreções e excreções baba e fez̧es e as características físicas mocho e troncho, resultando em 38 questões. Embora - na visão das pesquisadoras - tenha-se elaborado as perguntas de forma o mais clara e precisa possível, a fim de se assegurar ao informante a rápida apreensão do objetivo delineado pelo entrevistador, optou-se por apresentar a figura de um bovino, apontando nela a maioria das partes de que se desejava a nomeação.

Quanto ao uso de figuras, Ferreira e Cardoso (1994, p. 31) consideram:

Nesse caso, o uso de gravuras, perfeitamente traçadas, para serem descritas pelo informante apresenta uma dupla vantagem: de um lado permite que 
o informante [...] sirva-se das formas lexicais que se quer apurar; de outro, permite uma maior homogeneização do comportamento dos inquiridores no sentido de formular, com menor grau de diferenciação, as mesmas questões a diferentes informantes.

Assim, mesmo se utilizando a fotografia como apoio, a realização da lexia pata mostrou certa resistência do informante que exigiu as modificações descritas a seguir. Inicialmente, a pergunta consistia em Para o boi ficar em pé, em que ele se apóia? Depois de submetida à avaliação, percebeuse que uma outra construção, comparando o corpo do animal ao do homem, poderia facilitar a compreensão pelo informante e evitaria a substituição de pata por casco. Então, foi modificada para Para as pessoas ficarem em pé, elas têm as pernas. E o boi? O que ele tem para ficar em pé? A essa pergunta acrescia-se são essas partes aqui, apontando-as na fotografia. No entanto, não havia sido previsto que são usadas designações diferentes para os membros traseiros e dianteiros. Dessa forma, percebida essa falha, procedeu-se à inclusão de mais duas questões, que eram feitas utilizandose, simultaneamente, a fotografia de um bovino: Como se chamam as patas da frente? E as de trás? Essa última versão permitiu que a coleta de dados fosse mais abrangente e, portanto, eficiente.

Outras questões que apresentaram necessidade de adaptação, ainda no campo semântico partes do bovino, foram aquelas relativas a baba, bucho, traseiro e troncho. Para a primeira, a princípio, elaborou-se a questão: Como é chamada aquela gosma que sai da boca do boi quando ele está mastigando? Entretanto, o emprego de gosma poderia provocar uma repetição desse registro pelo informante, comprometendo o resultado da pesquisa. Assim, reformulou-se para: O que sai da boca do boi quando ele está mastigando? Tem outro nome?

Outro caso refere-se a bucho. Inicialmente, com base no conhecimento do próprio mundo de uma das pesquisadoras, elaborou-se a pergunta: Como se chama aquela parte do boi que a gente tem que limpar bem, pôr 
para cozinhar com feijão branco, que alguns chamam de dobradinha?, acreditando ser um prato da culinária brasileira, comum a todas as regiões e a todas as classes sociais. Essa questão, no entanto, apresentou dificuldades particulares. A primeira delas é relativa à complexidade e extensão da pergunta. As questões devem ser o mais objetivas e curtas possível. Observe-se que foi descrito todo um processo para que fosse nomeado um órgão do bovino. O segundo obstáculo diz respeito ao uso da palavra dobradinha, item lexical bastante produtivo em nossa região, para designar aquele prato preparado com o estômago do animal, mas que se revelou desconhecida pelo informante. Por outro lado, se se pretende, em seguida, investigar comidas feitas com o bucho, não se deve usar um registro possível na fala do informante, já que isso poderia favorecer o uso da variante que, talvez, ainda que conhecida, não seja própria da região. Assim, optou-se pela forma Quando o boi come, para onde a comida vai? Foi, ainda, acrescentada à questão Tem outro nome? a fim de registrar alguma outra variante. Essa construção mostrou-se mais produtiva no decorrer da coleta de dados.

Com relação a traseiro, percebeu-se, durante as entrevistas, que se obtinha, também, quarto traseiro. Para obter as duas realizações, permaneceu a questão Como é chamada a parte de trás do animal (apontar na foto) e acrescentou-se Como se chama um lado só do traseiro? Com isso, foi possível registrar uma variante que não estava, inicialmente, prevista na coleta de dados cujo conceito passou a integrar o rol das questões dada a sua produtividade na prática.

De maneira semelhante, não havia uma questão para a obtenção de variantes para troncho, lexia que recobre o conceito de animal sem orelha ou com orelha caída. A realização de algumas entrevistas permitiu que se atentasse para esse fato e que se incluísse a pergunta Quando o boi não tem orelha, ou a orelha é caída, como ele é chamado? Assim, buscava-se mais uma variante regional possível, de forma a tornar o questionário mais adequado e completo para a investigação léxico-dialetal desse campo da atividade humana. 
Percebeu-se, ainda, após as primeiras entrevistas, que a questão relativa à cara - Em que parte do boi ficam os olhos, as orelhas e as ventas? - não se mostrou produtiva. Os informantes respondiam cabeça, não se registrando nenhuma ocorrência da lexia que se buscava. Dessa forma, percebendo a generalização, optou-se por excluir essa pergunta nas gravações seguintes, permanecendo somente aquela referente à cabeça: Como é chamada a parte em que ficam a cara, os chifres e as orelhas do boi?

Após as aplicações experimentais do questionário na pesquisa de campo, verificou-se, ainda, que a questão relacionada a fežes deveria ser excluída por não se mostrar relevante ao campo léxico do gado devido ao fato de que constitui uma secreção comum aos animais, não sendo exclusiva dos bovinos. Da mesma forma, incluiu-se a questão Por onde sai a urina do boi? relativa ao órgão sexual do macho que não constava da versão anterior.

Para o campo semântico alimentação, foram elaboradas 10 questões. Dentre essas, merece destaque a pergunta para a obtenção de ração, sal e capim. Inicialmente havia apenas uma construção para as três lexias: $O$ que o gado come? Entretanto, para os informantes, o gado, naturalmente, não se alimenta de ração, tampouco ingere sal, a não ser que isto lhe seja oferecido. Assim, a resposta mais provável seria apenas capim. A pergunta para ração sofreu modificação para Como se chama aquilo que se põe no cocho para o gado comer?, pois no cocho, para comer, só se põe ração ou trato, excluindo-se, assim, capim. Para sal, ficou estabelecido $O$ que se põe no cocho para o gado lamber?, já que, para os que lidam com o gado, este não come sal, mas lambe-o.

Quanto aos cortes de carne e pratos feitos com carne bovina, na versão final do questionário, contou-se com 17 questões. Optou-se por agrupar os cortes e os pratos de carne bovina em um só bloco pelo fato de que aqueles são efetuados visando a um melhor aproveitamento da carne pela culinária, pois, para o armazenamento e conservação, seria desnecessário separar os pedaços obedecendo a algum critério. Submetidas à avaliação, permaneceram apenas as questões relacionadas aos cortes mais comuns 
na região e, ainda, às comidas mais populares e menos elaboradas, que exigem ingredientes facilmente encontrados na localidade. Assim, a questão O senhor conhece uma comida que é feita com pedacinhos de carne com creme de leite? relativa a strogonoff ou picadinho, foi eliminada. Outro caso de inadequação para esse campo semântico diz respeito à variante norte-paranaense bisteca, cujo corte não é próprio da região, sendo excluída tal questão no questionário definitivo. Também se fez necessária a inclusão da questão Como se chama aquela comida feita com o osso da pata da vaca? que não constava da versão inicial do questionário, cuja resposta mocotó foi bastante produtiva na pesquisa.

Parasitas, doenças, cirurgias e remédios próprios do gado bovino mostrou ser um campo semântico bastante produtivo, com 33 questões. Isso se deve ao fato de terem sido abordados não somente os problemas que afetam a saúde dos animais, mas também os procedimentos do tratamento. Nesse caso, algumas perguntas tiveram de ser eliminadas ou modificadas para que não houvesse interferência do entrevistador na obtenção dos dados e, também, para que não se buscasse em vão unidades léxicas que não integram o falar da comunidade. Alguns desses casos são comentados a seguir.

As perguntas que buscavam os nomes para medicamento injetável e put on ou sistêmico mostraram-se imperfeitas e improcedentes. Para o primeiro caso havia Como se chama o remédio para o gado que se aplica através de injeção? E para o segundo Como é chamado o remédio que se aplica colocando um fio no lombo do boi? A inadequação da primeira questão refere-se ao fato de que, apesar de ser amplamente empregada, a medicação injetável não é de uso exclusivo em animais e, portanto, não constitui um ponto relevante para a composição do léxico do gado. Considere-se, ainda, que injetável é um item lexical próprio da variante culta. No outro caso, além de as respostas esperadas serem improváveis na fala dos informantes por serem, também, próprias do padrão culto, a construção da pergunta não permitia a compreensão necessária para se proceder à resposta. Isso se dá pelo 
emprego de fio que pode ser entendido como material elétrico e não como uma porção de líquido despejada sobre o lombo do animal, causando confusão. Dessa forma, ambas as questões foram eliminadas.

A questão Qual é a doença que dá no boi e que ele fica mancando? Tem que tomar vacina também. foi modificada para Qual é a doença que deixa o animal travado, amuado, sem coordenação e acaba matando ele? Tem que tomar vacina também. Note-se que a primeira versão além de poucas informações incluía semas bastante genéricos sobre a doença, dificultando a obtenção da resposta. As alterações, com a inclusão de outras informações complementares, tornaram-na mais eficaz.

Houve, ainda, alteração na pergunta relativa a doenças do casco: Como se chama a doença que dá no meio do casco do boi por causa de andar em lugar umido? que passou para uma pergunta mais enumerativa: $O$ senhor conhece doenças que dão no casco? A primeira formulação estaria restringindo a resposta, provocando somente o registro de frieira ou outra variante. A construção definitiva mostrou ser mais abrangente e, ainda, mais direta e de fácil compreensão.

A questão Que doenças pode ter a vaca que criou? mostrou-se muito abrangente pelo fato de incluir qualquer fêmea que tenha criado alguma vez, não importando se foi há pouco ou há muito tempo. Isso prejudicaria a investigação de doenças provocadas pelo parto. Observada a inadequação, elaborou-se a forma Que doenças pode ter a vaca logo depois que cria? construção que se apresentou mais satisfatória.

Outra pergunta também relativa a doenças necessitou de reformulações. Essa questão inadequada, denunciada pela dificuldade de alguns informantes ao respondê-la, pôde ser percebida somente durante a fase das entrevistas definitivas. Essa diz respeito à variável curso: Como é chamada a doença que causa muita dor de barriga no bezerro ainda novinho? Uma das respostas obtidas foi dor de barriga, expressão encontrada na própria pergunta. O uso de uma variante possível na fala do entrevistado durante a coleta de dados pode interferir na fidedignidade do corpus constituído, já

SIGNUM: Estud. Ling., Londrina, n. 5, p. 9-47, dez. 2002 
que não há como atestar que esse mesmo registro seria obtido caso a formulação da pergunta fosse outra. Assim, preferiu-se a forma Como é chamada aquela doença que dá no bez̧erro quando ele é bem novinho, que ele faz muito cocô?

Finalmente, ainda nesse grupo semântico, merece ser comentada a lexia carrapato estrela, cuja pergunta era Como se chama o carrapato que dá em cavalo? Uma análise detalhada da questão indicou que o problema não estava na elaboração da questão, que era simples e direta, mas no fato de se configurar um caso de inadequação lexical. Apesar desse parasita ser próprio de um animal ligado à criação de gado, sua designação fugiria do campo léxico do gado vacum. Optou-se, portanto, por excluí-la.

Passando ao campo léxico faixas etárias e procriação, faz-se necessário esclarecer que este abordou as fases do nascimento do animal ao abate, ou à idade avançada do gado, quando não abatido, reunindo um total de 25 questões. Para macho e fêmea há designações diferentes e, somente depois da revisão dos dados obtidos nas aplicações experimentais, foi possível estabelecer questões que se mostraram mais produtivas. Em um primeiro momento foram formuladas descrições físicas dos animais em cada fase. Depois, optou-se por incluir a idade a fim de que se tornassem mais claras. Assim, antes constava Como é chamada uma cabeça de gado quando é um macho bem novinho? E se for uma fêmea? E posteriormente foi modificada para Como é chamada uma cabeça de gado quando é um macho bem novinho, quando não tem um ano ainda? E se for uma fêmea? $\mathrm{O}$ mesmo ocorreu com a questão E um macho nem novinho nem adulto, como é chamado? na qual foi acrescentada a informação quando tem entre 12 e 30 meses. Para obter a designação para o animal do sexo feminino nessa idade, apenas trocou-se a palavra macho por fêmea. Para a variante touro, elaborou-se Como é chamado o macho quando já pode ter filhote? Depois preferiu-se a forma Como é chamado o macho adulto inteiro? A segunda opção mostrou ser mais clara, evitando a possível repetição do termo garrote, obtido na questão anteriormente comentada. Outra pergunta também mereceu atenção. Trata-se da que recobre o 
conceito sobre cio. A forma Como é chamada a época do ano em que a vaca está pronta para cruzar? foi substituída por Quando a vaca está nos dias para cruzar, se dir que ela está no quê? Dessa forma, evitou-se que época fosse confundida com estações ou meses do ano, o que alteraria a resposta.

Para a investigação do campo semântico raças, cores e outras características físicas foi suficiente a composição de 13 perguntas. Com a finalidade de facilitar as respostas a respeito das cores, foram utilizadas fotografias de animais com diferentes pelagens, evitando que a interpretação das descrições fossem heterogêneas. Ainda tratando-se das cores, decidiu-se incluir algumas questões com a finalidade de verificar se algumas realizações retiradas dos contos O Burrinho Pedrês e Conversa de Bois, de João Guimarães Rosa, seriam utilizadas ou conhecidas pelos informantes. Cumpre esclarecer que Camapuã é uma região matogrossense para onde migrou uma grande leva de mineiros durante os anos 80. As perguntas Conhece outras cores? Como são? também foram acrescentadas a fim de se obter o maior número possível de registros para as cores. Assim, as características da pelagem, omitidas pelo número limitado de fotografias, seriam obtidas com essa questão.

A verificação das realizações para gado de corte e gado leiteiro foi também incluída no campo raças, cores e outras características pelo fato de que, de acordo com a finalidade do rebanho, há raças específicas, o que significa padrões físicos diferentes. Assim, estabeleceu-se Como é chamado o gado que serve para dar leite? Tem outro nome? e Como é chamado o tipo de gado que não é bom de leite e só serve para dar carne? Tem outro nome? Da mesma forma, a pergunta Como é chamado um animal ruim para a engorda? foi inserida nesse campo, pois, nesse caso, inclui certas características físicas, resultado de cruzamentos, que determinam o baixo rendimento de peso. Apenas a pergunta para o registro de boi marruá ou alongado, que se refere a traços comportamentais e não físicos, pode parecer, à primeira vista, estar no grupo inadequado. No entanto, por se tornarem praticamente selvagens, devido ao fato de viverem embrenhados no cerrado, formam um grupo 
bastante distinto dos outros animais, como se fossem de uma raça específica. Por essa particularidade, optou-se por incluir essa variável no referido campo semântico.

Para a verificação dos registros das diferentes raças, a princípio, formularam-se questões partindo das características de cada uma. Entretanto, os dados físicos não são suficientes para diferenciar uma raça da outra, visto que, devido aos cruzamentos, muitas são semelhantes. Também se poderia elaborar perguntas do tipo: Qualé a raça que dá cruzando nelore com charolês? No entanto, seria bastante improvável encontrar informantes com conhecimento suficiente sobre os diversos cruzamentos industriais para reconhecer as raças. Preferiu-se, portanto, eliminar questões como Como se chama a raça de gado que tem uns chifres bem grandes?; Qual é o gado mais conbecido que tem cupim e chifre? E se o gado tiver cupim, mas não tiver chifre? Para substituí-las, formulou-se Quais são as raças de gado que o senhor conbece?(Pedir para descrever se não souber a que se refere.) Essa última forma mostrou-se bastante adequada aos propósitos da pesquisa.

A elaboração das questões para obtenção de registros relativos ao transporte não apresentou grandes dificuldades, caracterizando-se pela simplicidade e objetividade. Também não constitui um campo semântico muito produtivo, abrangendo apenas 12 variáveis. Apenas a questão Como são chamados os homens que vão ao lado dos animais na comitiva? merece ser ressaltada. Esta foi incluída com a finalidade de verificar se havia uma designação especial para a referida posição do condutor de gado, já que, enquanto as posições anterior e posterior aos animais são comumente nomeadas, a realização possível para a lateral permanecia desconhecida até o momento da aplicação do questionário.

O campo semântico comércio resultou em uma pequena amostra lexical, sendo investigados apenas 4 conceitos: leilão, lote, vaca magra ou boiadeira e boi magro. Para a obtenção de lote, seria usada a construção Como se fala quando se tem vários animais, vacas, ou bois, ou tudo misturado, juntos, para ir para o leilão, por exemplo? Essa forma apresentou-se muito abrangente e 
confusa, não descrevendo especificamente um lote. Assim, foi modificada para Como é chamado cada um daqueles grupos de cabeças compradas no leilão? e que se mostrou mais adequada.

Foram investigadas as variantes possíveis para dez conceitos em trabalhadores, animais e serviços relacionados à pecuária. Para obtenção de veterinário, ou sua variante, inicialmente havia Como se chama o médico que trata só de animais? Consistindo médico em uma resposta possível, optou-se por Como é chamado o profissional que estuda só para cuidar de animais? Além dessa, foi necessário reformular, também, a pergunta relativa a dar rodeio. Primeiro formulou-se Como se chama o trabalho de cuidar do gado? Essa forma não se mostrou específica o suficiente, não servindo, portanto, aos propósitos determinados. Após a reformulação, obteve-se Como é chamado o trabalho de ir a cavalo no pasto e olhar todos os animais para ver se não tem nenhum doente? Excetuando-se essas questões, as demais não apresentaram dificuldades para a compreensão do informante.

Para vestuário próprio para a lida foram elaboradas 5 questões, não consistindo em um campo semântico muito produtivo. Foram apenas 4 questões que descreviam a peça a ser nomeada, e uma última, que indagava: Tem outra peça de roupa que o peão usa na lida? As questões desse campo semântico mostraram-se produtivas, considerando que os entrevistados não apresentaram dificuldades ao respondê-las.

Quanto a divisões da propriedade e madeiras utilizadas nessas divisões, nove conceitos foram observados. Duas questões relativas a essas variáveis merecem destaque. A primeira, relativa a colchete, ainda na fase de elaboração e reelaboração, exigiu uma pequena alteração: substituiu-se troncos finos de árvore - Como se chama aquele tipo de porteira que é feito com arame e uns troncos finos de árvore? - por lascas - Como se chama aquele tipo de porteira feito com lascas e arame? - designação mais comum na região e que garantiria a compreensão do objeto descrito. A segunda refere-se à variável porteira. Durante as entrevistas, percebeu-se inadequada a construção Como é chamado aquele portão de madeira por onde as pessoas passam, de carro ou a pé, para entrar numa 
faženda ou num pasto? Portão constitui uma variante de porteira na região. Assim, a fim de não influenciar a resposta do informante, alterou-se a pergunta para Pra entrar numa fazenda ou em um pasto, o que é que a gente tem que abrir, que é feito de madeira?

O campo semântico instrumentos reuniu um total de 20 lexias possíveis na fala dos informantes da região. Observa-se que algumas delas poderiam ser incluídas em outros grupos já existentes. No entanto, optou-se por formar um bloco em separado por considerar que se ganharia em organização. Dessa forma, partiu-se para a formulação das perguntas, tarefa que não apresentou maiores dificuldades, excetuando-se a questão referente a laço. A inadequação ocorreu devido à falta de conhecimento, por parte do pesquisador, a respeito do objeto. Observa-se que primeiramente constava Como é o nome do negócio feito de corda que se usa para segurar o boi e colocá-lo dentro do caminhão, por exemplo, quando ele não quer entrar? O equívoco está em que o laço é feito de couro. Assim, corda e laço constituem objetos distintos. Após o conhecimento dessa particularidade, a primeira versão foi reformulada para Como se chama aquele negócio feito de couro que o peão leva no cavalo e serve para pegar um animal para derrubá-lo ou para arrastá-lo para o caminhão, por exemplo? Além da troca de corda por laço, também foi acrescentada a informação que o peão leva no cavalo e serve para derrubar o animal, adequando a pergunta ao seu propósito. Após o início das entrevistas, foram incluídas duas outras questões para a nomeação de mochador e berrante, no intuito de verificar o maior número possível de variantes nesse campo semântico.

Em comportamentos e atitudes do gado bovino buscou-se obter 6 registros possíveis para designação de certas ações inerentes ao gado bovino, de forma exclusiva ou não. O número de registros a serem investigados podem indicar que esse não consistiu em um campo semântico muito produtivo. Com relação à composição, somente a pergunta para a obtenção de coice necessitou de adequações. A primeira versão para a obtenção dos nomes que recobrem esse conceito consistia em Quando o boi machuca alguém com as 
patas de trás, o que ele fea? e foi reformulada para Quando o boi está bravo, o que ele pode dar nas pessoas que estiverem atrás dele? Esta forma ganhou em clareza e objetividade, permitindo a compreensão exata do que se pretendia nomear.

O último bloco incluiu 4 questões de elocução livre. O objetivo de incluí-las nesta pesquisa vai além da investigação do léxico, embora houvesse a possibilidade de obter a realização de algumas das variáveis investigadas. Sobre a validade dessas perguntas, Ferreira e Cardoso (1994, p. 30) afirmam:

Uma outra hipótese de trabalho pressupõe que a recolha dos dados se faça mediante a aplicação de um questionário ou através de conversa livre. A opção, porém, pela primeira hipótese não exclui a segunda, ao contrário, a boa técnica recomenda que, aplicado o questionário formal, se registrem alguns minutos de conversa livre sobre tema que poderá ser relacionado a uma das atividades do informante ou predominante na região, ou, então, totalmente livre, incluindo-se relatos pessoais e narrativas de diferentes gêneros.

A importância dessas questões reside no fato de que se configura uma oportunidade de se registrar uma fala menos cuidada e mais próxima do falar da região, reunindo além de material para futuras pesquisas, a possibilidade de ocorrência de outras variantes.

\section{Considerações finais}

A elaboração das questões que compõem o questionário para a pesquisa sobre o léxico do gado em Camapuã, como se procurou demonstrar, consistiu em uma tarefa extremamente cuidadosa, com muitas formulações e reformulações. Este trabalho, delicado, insistente e permanente de lapidação constitui a única via para se atingir o grau de precisão indispensável ao trabalho científico.

SIGNUM: Estud. Ling., Londrina, n. 5, p. 9-47, dez. 2002 
Ficou evidente, mais uma vez, que a língua de especialidade que se busca registrar exige, além da cultura livresca, o saber fazer, isto é, a imersão no contexto social do informante, no seu cotidiano, na sua prática. Tornase condição fundamental para o êxito da composição de questionários destinados à pesquisa de campo e à organização de glossários o domínio das etapas da atividade em estudo.

A composição e aplicação de questionários lingüísticos constitui uma tarefa bastante complexa. Assim, há, ainda, algumas observações a serem feitas com a finalidade de contribuir para a elaboração de inquéritos eficientes.

Embora esse fato já tenha sido abordado anteriormente, faz-se necessário ressaltar a importância de o pesquisador tomar conhecimento das características sócio-culturais e econômicas do grupo social a ser pesquisado buscando, sempre que necessário, a colaboração de pessoas ligadas à comunidade. A falta de informações resultará em um questionário por demais restrito no que tange à obtenção dos dados lingüísticos e, dessa forma, a pesquisa será pouco representativa.

Outro ponto a ser considerado diz respeito à dinâmica da língua. Sabendo que esta se encontra em constante mudança e adequação, o mesmo deve ocorrer com o questionário lingüístico. Esse instrumento de coleta de dados precisa acompanhar a evolução da língua e da sociedade, sofrendo alterações sempre que se julgar necessário. Dessa forma, não se pode pensar em um inquérito perene, que servirá a gerações de estudiosos. No caso específico do léxico do gado, por exemplo, o avanço da tecnologia tem chegado ao campo, trazendo novas formas de manejo, novos instrumentos, o que significa a incorporação de novas lexias no falar dos profissionais ligados à atividade pecuária. Daqui a cinco anos, quando obrigatoriamente, todos os criadores deverão ter implantado um sistema moderno de controle do rebanho, uma nova pesquisa poderá ser feita e, certamente, serão registradas outras variáveis lingüísticas, não previstas no questionário atual. 
Observa-se, ainda, que as questões do questionário do léxico do gado foram formuladas partindo de uma linguagem simples, mas obedecendo às normas do padrão culto. No entanto, o inquiridor terá liberdade para adequar sua linguagem à linguagem do informante. Isso constitui mais do que uma opção. É imprescindível ao entrevistador ter tanto consciência como competência lingüística a fim de que sua modalidade de fala não acarrete prejuízos à pesquisa. O informante poderá vencer a inibição que sente devido à presença do gravador, mas dificilmente falará com naturalidade se o pesquisador construir uma barreira lingüística entre ambos.

Ainda com relação à aplicação do inquérito, vale ressaltar que perguntas que possam causar constrangimento ao informante pelo fato de o inquiridor ser do sexo feminino são passíveis de ser realizadas por um entrevistador auxiliar masculino, estabelecendo, assim, uma relação de confiança, contribuindo para o registro de dados fidedignos. Como exemplo, pode-se citar questões como Por onde o filhotinho da vaca sai quando nasce? No caso do questionário do léxico do gado, perguntas desse tipo foram feitas por um colaborador do sexo masculino, já que, para essa pesquisa, não foram tomadas mulheres como informantes.

Quanto às respostas que se pressupõe obter quando da composição de cada pergunta componente do questionário, cabe ressaltar que são, muitas delas, imprevisíveis. Encontra-se nesse fato a motivação para a pesquisa lingüística que busca, constantemente, o conhecimento dessa pluralidade.

Ao terminar essas exposições, espera-se facilitar o trabalho de outros lingüistas que procuram, também, registrar e compreender as faces da língua portuguesa. As etapas de construção do questionário detalhadamente descritas, as inadequações verificadas em diversas questões, as soluções propostas e, enfim, o questionário na sua versão final poderão balizar a elaboração de outros inquéritos que resultarão no conhecimento de diferentes esferas lingüísticas. 


\section{ANEXO \\ Questionário: Léxico do Gado Bovino do Município de Camapuã (MS)}

\section{Partes do Corpo}

(Pode ser utilizada a foto de um bovino, com a finalidade de se apontar as partes do corpo visíveis, complementando as perguntas.)

1. Como é chamada aquelas pontas que o boi tem na cabeça? (Pode-se apontar na foto.) - (chifre)

2. Quando o boi não tem chifres, como ele é chamado? (mocho)

3. Quais são as partes do chifre? (pé/ponta; sabugo/chifre)

4. Quais são os diferentes formatos de chifres que existem? Como são? Têm nome? (banana)

5. Como são chamados aqueles fiozinhos curtinhos que cobrem o corpo do boi? (pêlo)

6. Qual é a parte do boi que serve para fazer bota, arreio, cinto...? (couro)

7. Como é chamada a parte da frente do boi? (Pode-se explicar que inclui a cabeça, as patas e apontar na foto.) - (dianteiro)

8. Como é chamada esta parte do boi? (Apontar na foto.) - (paleta)

9. Como é chamada a parte de trás do animal? (Pode-se apontar na foto.) (traseiro)

10. Como se chama um lado só do traseiro? (quarto/ quarto traseiro)

11. Como é chamada aquela parte do boi que fica pendurada no traseiro e que ele usa para espantar os mosquitos? (Pode-se apontar na foto.) - (rabo)

12. Como é chamada a ponta do rabo, onde tem aqueles pêlos compridos? (Pode-se apontar na foto.) - (vassoura/cola)

13. Qual é a parte do corpo que o boi usa para enxergar? (olhos/vista) 
14. Como são chamados aqueles dois buraquinhos que o boi usa para respirar? Têm outro nome? (pode-se apontar na foto.) - (nariz/ventas/focinho)

15. Se for um buraquinho só, como é chamado? (narina)

16. Quando o boi come, para onde a comida vai? Tem outro nome? (estômago/ bucho)

17. Por onde o resto de comida sai? (ânus)

18. Como se chama aquilo que fica do lado do chifre e serve para o boi escutar? Tem outro nome? (Pode-se apontar na foto.) - (orelha)

19. Quando o boi não tem uma orelha ou a orelha é caída, como ele é chamado? (troncho)

20. Em que parte do boi ficam os olhos, as orelhas, as ventas, os chifres? Tem outro nome? (cabeşa)

21. Como é chamada aquela parte que fica entre a cabeça e o corpo do boi? (Pode-se apontar na foto.) Corresponde a esta parte nas pessoas. (Apontar o pescoço.) - (pescoso o)

22. Como é chamada a parte de cima do boi? (Pode-se apontar na foto.) Corresponde a esta parte nas pessoas (Apontar as costas.). (lombo)

23. Como é chamada aquela bola que tem atrás do pescoço, no lombo do boi? (cupim)

24. Para as pessoas ficarem em pé, elas usam as pernas. E o boi? O que ele usa para ficar em pé? Têm outro nome? (Pode-se apontar na foto.) - (patas)

25. Como se chamam as patas de trás? (Pode-se apontar na foto.) - (pés)

26. E as patas da frente? (Pode-se apontar na foto.) - (mãos)

27. Como chama aquela parte de baixo da pata, que é partida e em que o animal se apoia para ficar em pé? Tem outro nome? (Pode-se apontar na foto.) (casco)

28. Como é chamada esta parte do boi? Tem outro nome? (Apontar o próprio peito ou na foto.) - (peito/granito) 
29. Como é chamado aquele couro solto que vai do pescoço até o peito do boi? Tem outro nome? (Pode-se apontar na foto.) - (barbela)

30. O que tem dentro da boca do boi? (lingua, dentes)

31. Qual é a parte da vaca onde o filhotinho fica antes de nascer? Tem outro nome? (útero)

32. Qual é a parte da vaca que serve para dar de mamar? Tem outro nome? (teta) úbere)

33. Por onde o filhotinho da vaca sai quando nasce? (vagina)

34. Qual é a parte do boi arrancada para ele não enxertar mais e ficar mais gordo? (testiculo/bagos)

35. O que o bezerro tem na barriga que precisa ser curado quando nasce para não dar bicheira? (umbigo)

36. Como é chamada esta parte do boi? (Apontar o tendão de Aquiles no próprio corpo ou na foto.) - (jarrete/garrão/tendão)

37. O que sai da boca do boi quando ele está mastigando? Tem outro nome? (baba)

38. O que é que fica dentro da cabeça do boi e também serve para comer? (miolo)

\section{Cortes de Carne e Pratos Feitos Com Carne Bovina}

39. Como é chamada aquela carne do boi que tem uns ossos compridos e largos e que é tirada daqui? (Apontar as costelas no próprio corpo ou na foto.) (costelas)

40. Qual é a carne mais mole do boi? (filet mignon)

41. Qual é a carne de boi mais dura do boi? (pescoco)

42. Como é chamada a carne de boi quando é passada numa máquina para ficar em pedaços bem pequenininhos? (carne moída)

43. Quais são os outros nomes de carne de boi que o senhor conhece? (Pedir para explicar quando não souber o que é.) 
44. Como é chamada a comida feita com o estômago do boi? (buchada)

45. Como se prepara a buchada?

46. Como é chamada a comida feita com o rabo do boi? (rabada)

47. Como se prepara a rabada?

48. Como é chamada aquela comida que é feita assando a carne na brasa? (churrasco)

49. Como se prepara o churrasco?

50. Como é chamada a comida feita com carne e mandioca cozidos juntos? (vaca atolada)

51. Como se prepara a vaca atolada?

52. Que comida é feita com os testículos/bagos do boi? (farofa)

53. Como se prepara?

54. Como se chama aquela comida feita com o osso da pata da vaca? (mocotô)

55. Como se prepara?

56. Quais são as outras comidas feitas com carne de boi que o senhor conhece? (Pedir para explicar se não souber o que é.)

\section{Parasitas, Doenças, Cirurgias e Remédios Próprios do Gado Bovino}

57. Existe alguma doença que dá no chifre do animal?

58. Que remédio se usa para curar a doença que dá no chifre?

59. Como é chamada a doença que dá no bezerro quando ele é bem novinho, que ele faz muito cocô? (curso/tristezinha)

60. O senhor conhece algum capim que se comido pelo animal provoca dor de barriga?

61. Qual é a doença que dá feridas na boca e o gado tem de ser vacinado todo ano? (Explicar, se necessário, que se houver qualquer caso dessa doença, o Estado fica proibido de vender gado para outros Estados.) (aftosa)

SIGNUM: Estud. Ling., Londrina, n. 5, p. 9-47, dez. 2002 
62. Como são chamadas aquelas moscas que ficam em cima do boi, incomodandoo, não deixando o animal pastar direito? (Se necessário, frisar que são tantas que cobrem o lombo do animal.) (mosca do chifre)

63. Como combate a mosca do chifre?

64. Qual é o nome do bichinho que gruda no boi e chupa o sangue dele? (Podese acrescentar que também gruda nas pessoas, que é necessário aplicar algum remédio para caírem.) Conhece por outro nome? (carrapato)

65. Que remédio se usa para combater carrapato? Conhece outro nome? (carrapaticida/ vermifugo))

66. Como é chamado o bicho que dá dentro do couro, formando uns calombinhos? (Acrescentar, se necessário, que é provocado por moscas, são como larvas e geralmente tem apenas um bichinho em cada buraquinho.) (berne)

67. Que remédio se usa para combater berne? Conhece outro nome? (bernicidal vermifugo)

68. Às vezes o gado fica com uns calombos grandes no couro, cheios de pus e é preciso rasgar para sarar. Como eles são chamados? (tumores)

69. Como é chamada a ferida do boi quando está cheia de bichos? (Pode-se acrescentar que os bichos vêm de ovos postos por moscas, que estes bichos vão comendo o gado.) (bicheira)

70. Qual é a mosca que provoca bicheira no gado? (mosca varejeira)

71. Que remédio é usado para curar bicheira? Conhece outro nome? (mata-bicheira)

72. Conhece doenças que dão no casco?

73. Como são tratadas?

74. Como são chamados os bichos que ficam dentro da barriga do boi e não deixam que engorde? (vermes)

75. Qual é o remédio que se aplica no gado para acabar com os vermes? Conhece outro nome? (vermifugo) 
76. Como é chamada a doença que faz com que a vaca fique com o úbere/teta inflamado (a)? (mastite)

77. Como se trata essa doença?

78. Que doenças pode ter a vaca logo depois que cria?

79. Como são curadas essas doenças?

80. Para curar o gado de doenças, o senhor usa algum remédio caseiro, alguma erva ou árvore do cerrado? Quais são e para que servem?

81. Como chama a operação que serve para tirar os chifres do animal? (mochação)

82. Como é chamada a operação que se faz para tirar o bezerro da barriga da vaca? (cesárea)

83. Como é chamado o bezerro quando nasce defeituoso, com pernas tortas ou faltando uma parte do corpo? Conhece outros nomes? (aleijado/ náfego)

84. Qual é a doença deixa o animal travado, amuado, sem coordenação e acaba matando-o? (carbunculo)

85. Como se trata o carbúnculo?

86. O senhor conhece outras doenças que o gado pode ter? (Pedir para explicar se não souber o que é.)

87. Que remédios são usados para combatê-las?

88. O que se aplica no gado para que não pegue doenças? (vacinas)

89. Conhece alguma reza ou benzimento usado para curar doenças do gado? Qual?

\section{Faixas Etárias e Procriação}

90. Como é chamada uma cabeça de gado quando é um macho bem novinho, quando não tem 1 ano ainda? (bežerro)

91.E se for uma fêmea? (bezerra)

92. Como é chamado o macho quando não é nem novinho nem adulto? (Pode-

SIGNUM: Estud. Ling., Londrina, n. 5, p. 9-47, dez. 2002 
se dizer que tem entre 12 e 30 meses) - (garrote)

93.E se for uma fêmea nessa idade: nem novinha, nem adulta? (Pode-se dizer que tem entre 12 e 30 meses.) - (novilha)

94. Como é chamado o macho adulto inteiro? (Pode-se dizer que tem mais de 30 meses.) - (touro)

95. Como é chamado o macho adulto quando não tem os testículos? (boi/capão)

96. Como é chamada a fêmea quando já pode ter filhotes? (novilha)

97. Qual é a diferença entre novilha e vaca? (A novilha ainda não criou.)

98. O que é uma vaca solteira? (É a vaca que não criou, uma novilha)

99. Quando a vaca está nos dias para cruzar, se diz que ela está no quê? (cio)

100. Quando a vaca está esperando um filhote, se diz que ela está o quê? Tem outro nome? (prenhal enxertada)

101. Como se chama a vaca que está nos dias de criar? (chegada)

102. Que nome se dá para a vaca que não pega cria, não serve para enxertar? (falbada)

103. Como é chamada a vaca que não tem leite?

104. Como se chama a vaca quando dá bastante leite?

105. O que se diz que aconteceu quando a vaca cria antes da hora e o filhote nasce morto? (abortou)

106. Quando a vaca é boa de cria recebe algum nome especial? (parideira)

107. O que o bezerro é da vaca? (cria/filhote)

108. Quando o touro e a vaca namoram para ter um filhote, o que se diz que eles estão fazendo? (cruzando)

109. O se que diz da vaca quando ela está enxertada e dá para ver que está cheia de leite? O que está acontecendo? (Está mojando.)

110. Como se chama o filhote da vaca quando ainda está na barriga?(feto/ embrião/ bezerro) 
111. Que nome se dá quando nascem dois bezerros de uma vez só?(gêmeos)

112. Como se chama um animal quando já é mais velho, com mais de 30 meses ou pronto para o abate? (erado)

113. Que nome se dá ao bezerro separado da vaca para não mamar mais, quando tem, geralmente, sete meses? (desmama)

114. Se o senhor comprar uma vaca junto com o bezerro, o que se diz que comprou? Tem outro nome? (vaca parida)

\section{Alimentação}

115. O que o gado come? (capim, sal, ração/trato)

116. Que tipos de capim o senhor conhece? (brizantão, brachiária, tanzânia, mombaça...)

117. Como é chamado o lugar em que se põe água para o gado beber? (bebedouro)

118. Como é chamado o lugar em que se põe comida para o gado?(cocho)

119. Do que pode ser feito o cocho?

120. Quando o gado está comendo capim, o que se diz que ele está fazendo? (pastando)

121. Que nome se dá à criação de gado feita com ração num cercado pequeno? (confinamento)

122. E o gado criado assim, fechado, como se chama? (confinado)

123. Como se chama aquilo que se põe no cocho para o gado lamber? (sal)

124. Como é chamada a comida que se põe no cocho para o gado comer? Tem outro nome? (Pedir para explicar o que é se não souber.) - (ração/trato)

\section{Raças, Cores e Outras Características Físicas}

125. Quais são as raças de gado que o senhor conhece? (Pedir para descrever se não souber a que se refere.)

SIGNUM: Estud. Ling., Londrina, n. 5, p. 9-47, dez. 2002 
126. Quais são as cores destes animais? (Mostrar fotos de um álbum, com as fotos numeradas. Devem ser apresentadas na seqüência numérica.)

127. Como é um boi chitado? (Boi de pêlo branco e vermelho.)

128. Como é um boi jaguanês? (Boi com o fio do lombo e a barriga brancos e o lado das costelas preto ou vermelho.)

129. Como é um boi fumaço? (cinæa)

130. Como é um boi sapiranga? (Animal de olhos brancos, inflamados ou depilados.)

131. Como é um boi retinto?

132. Como é um boi chumbado? (Boi de pêlo branco, vermelho ou castanho com manchas pretas.)

133. Como é chamado o gado que serve para dar leite? Tem outro nome? (leiteiro)

134. Como é chamado o tipo de gado que não é bom de leite e só serve para dar carne? Tem outro nome? (gado de corte)

135. Quando o boi não tem chifres como ele é chamado? (mocho)

136. Como é chamado o boi que foge, fica longe do gado manso e acaba ficando muito bravo? (marruálalongado)

137. Como é chamado um animal ruim para a engorda? (agarradinho)

\section{Transporte}

138. Como é chamado o caminhão que serve para transportar o gado? Conhece outro nome? (boiadeiro)

139. Como se chama o caminhão quando é maior e cabem mais cabeças? Tem outro nome? (carreta)

140. Como é chamada a parte de trás do caminhão onde ficam os animais? (gaiola)

141. Como se chama aquele grupo de homens que se vê na estrada, levando o gado de um lugar para outro, montados em animais? (comitiva)

40

SIGNUM: Estud. Ling., Londrina, n. 5, p. 9-47, dez. 2002 
142. Como é chamado o homem que vai na frente do gado? (ponteiro)

143. Como é chamado o homem que fica atrás dos animais? (culatra)

144. Como são chamados os homens que vão ao lado dos animais na comitiva?

145. Como é chamado o homem que faz comida para a comitiva? (cozinheiro)

146. Como é chamado o lugar nas estradas próprios para as comitivas passarem? (corredor)

147. Onde as comitivas param para passar a noite? (pousos)

148. Como são chamados os gritos que os peões dão para chamar o gado? (aboio)

149. Como é chamado aquele trançado de couro que serve para bater no cavalo para andar mais rápido, ou no boi? (chicote/relho)

\section{Comércio}

150. Uma firma pode reunir num mesmo lugar pessoas que querem vender gado e outras que querem comprar. Então, o gado é mostrado e aquele que pagar mais leva. Como é chamada essa forma de comercializar gado? (leilão)

151. Como é chamado cada um daqueles grupos de cabeças compradas no leilão? (lote)

152. Que tipo de fêmea se compra para a engorda? (vaca magral vaca boiadeira)

153. Que tipo de macho se compra para a engorda? (boi magro)

\section{Trabalhadores, Animais e Serviços Relacionados à Pecuária}

154. Como é chamado o homem que cuida de uma fazenda para o dono? (gerente/ administrador)

155. Como é chamado o trabalho de ir a cavalo no pasto e olhar todos os animais para ver se não tem nenhum doente? (dar rodeio)

156. Quando alguém passa remédio no gado para secar uma bicheira ou o umbigo,

SIGNUM: Estud. Ling., Londrina, n. 5, p. 9-47, dez. 2002 
o que a pessoa está fazendo? (curando)

157. Como é chamado o homem que lida com gado? Tem mulher que trabalha com gado? Como é chamada? (peão/peoa)

158. Como é chamado o profissional que estuda só para cuidar de animais? (veterinário)

159. Como é chamado o trabalho de separar uma rês de outra para formar lotes ou para curar? (apartação)

160. Em que animais os peões montam para lidar com o gado?

161. Qual é a diferença entre eles?

162. Quando um cavalo ou burro é bom para a lida com o gado, ele recebe algum nome especial? Qual é?

163. Quando o animal é ruim para a lida, recebe algum nome especial?

\section{Vestuário}

164. O que o peão usa na cabeça? (chapéu)

165. O que o peão usa no pé? (bota/botina)

166. Como é chamado aquele couro que o peão usa por cima da calça para proteger as pernas?

167. O que o peão usa para se molhar menos nos dias de chuva? (capa)

168. Tem outra peça de roupa que o peão usa na lida?

\section{Divisões da Propriedade e Madeiras Utilizadas Nessas Divisões}

154. Como é chamado o lugar com várias divisões em que se reúne o gado para curar, marcar, apartar? (mangueira)

169. Como se chama o lugar onde se reúne o gado para fazê-lo entrar na mangueira? (manga)

170. Como é chamado o lugar dentro da mangueira em que se prende o animal 
para curar ou castrar? (tronco/brete)

171. Quais são as madeiras que o senhor conhece boas para fazer cerca? (aroeira, itaúba)

172. Para entrar em uma fazenda ou em um pasto, o que é que a gente tem que abrir, que é feito de madeira? (porteira)

173. Como chama aquele tipo de porteira feito com lascas e arame? (colchete)

174. Como é chamada aquela madeira usada para o arame da cerca ficar esticado? (balancim)

175. Como é chamado aquele terreno cheio de capim onde o boi come? (pasto)

176. Quando o pasto é dividido em partes menores para aproveitar melhor a área, como este cercados são chamados? (piquete)

\section{Instrumentos}

177. O que se usa para pesar o gado? (balança)

178. Como se chama aquela rampa que serve para o boi entrar ou sair do caminhão? (embarcadouro)

179. Como se chama aquele negócio feito de couro que o peão leva no cavalo e serve para pegar um animal para derrubá-lo ou para arrastá-lo para o caminhão, por exemplo? (laço)

180. O que se usa para amarrar as pata de um animal para curar ou para tirar leite? (peia)

181. Como se chama aquela roda que o peão faz com laço e serve para laçar um animal? (rodilha)

182. Como é chamado aquele ferro que se esquenta para fazer um sinal no animal para saber depois a quem pertence? (marca)

183. Como é chamada aquela plaquetinha que se coloca na orelha do animal para controle? (brinco)

184. Como é chamado aquele ferro redondo que se coloca nas ventas do animal

SIGNUM: Estud. Ling., Londrina, n. 5, p. 9-47, dez. 2002 
para levá-lo de um lugar para outro? (argola)

185. Como é chamada aquela espécie de alicate/turquês que se prende no nariz do animal para ele obedecer? (formiga)

186. Como chama o instrumento que se usa cutucar o gado para ele entrar, por exemplo, na mangueira ou no caminhão? (ferrão)

187. Como é chamada aquela peça de madeira que se coloca no pescoço da rês para ela não pular a cerca? (canga)

188. Como se chama aquilo que se coloca na cabeça do boi para puxá-lo de um lugar para outro? (cabresto)

189. Como é o nome do instrumento que se usa para castrar o touro sem precisar fazer corte? (burdizo)

190. Como se chama o ferro que serve para mochar o boi? (mochador)

191. Como é chamado aquele ferro em que se põe a carne para assar na brasa? (espeto)

192. Como se chama aquela grade que se coloca em cima da brasa para pôr a carne para assar? (grelha)

193. Como é chamado o aparelhinho que se usa para dar injeção no gado que parece uma arma? (revólver)

194. Como é chamado aquele tubinho de plástico com uma agulha na ponta e também serve para dar injeção no gado? (seringa)

195. O que o peão usa no pé para cutucar o cavalo para andar mais rápido? (espora)

196. Como se chama aquele instrumento feito de chifre, comprido, que se assopra nele e serve para chamar o gado? (berrante)

\section{Comportamentos e Atitudes do Gado Bovino}

197. Como se chama o machucado que o boi faz em alguém com o chifre? (chifrada) 
198. Quando o boi está bravo, o que ele pode dar nas pessoas que estiverem atrás dele? (coice)

199. Quando o boi está bravo, que fica respirando alto, o que se diz que ele está fazendo? (bufando)

200. Quando o boi pula a cerca, o que se diz que ele fez? (vazou)

201. O cachorro late, o gato mia. E o que o boi faz? (muge/ berra)

202. O gado sempre deita e fica mastigando, mastigando. O que ele está fazendo? (ruminando)

\section{Elocução Livre}

203. Por que o senhor escolheu essa profissão?

204. O senhor conhece alguma história triste que aconteceu com algum boiadeiro da região?

205. O senhor conhece alguma história engraçada que aconteceu com outro boiadeiro?

206. Já aconteceu alguma história interessante com o senhor? 


\section{Bibliografia}

AGUILERA, Vanderci de Andrade. Aspectos lingüisticos da fala londrinense. Esboço de um atlas lingüístico de Londrina. Londrina: UEL, 1987.

ALTINO, Fabiane Cristina. Pelos caminhos da geolingüistica paranaense: um estudo do léxico popular de Adrianópolis. 2001. Dissertação (Mestrado em Letras) - Universidade Estadual de Londrina, Londrina.

BAERNERT-FUERT, Ute. Flashes metodológicos: a sociolingüística qualitativa/quantitativa. In: TARALLO, Fernando. Fotografias sociolingüísticas. Campinas: Ed. Pontes, 1989.

BORTONI-RICARDO, Stella Maris. Problemas de comunicação interdialetal. Tempo Brasileiro, 78/79, Rio de Janeiro, jul./dez. 1984.

CASTRO, Cynthia Delmonaco. O vocabulário da cultura do café. 2001. Dissertação (Mestrado em Letras) - Universidade Estadual de Londrina, Londrina.

FERREIRA, Carlota; CARDOSO, Suzana. A dialetologia no Brasil. São Paulo: Contexto, 1994.

FISHER, John L. Influências sociais na escolha de variantes lingüísticas. In: FONSECA, Maria Stella Vieira; NEVES, Moema Facure (Org.) Sociolingüistica. Rio de Janeiro: Eldorado, 1974.

LABOV, William. Estágios na aquisição do inglês standard. In: FONSECA, Maria Stella Vieira; NEVES, Moema Facure (Org.) Sociolingüística. Rio de Janeiro: Eldorado, 1974.

LAMBACH, Jane Bernadete. Vocabulário da cachaça: resgate e memória. 2002. Dissertação (Mestrado em Letras) - Universidade Estadual de Londrina, Londrina.

RECTOR, Monica (Org.). Questionário básico de trabalho de campo lingüistico. Rio de Janeiro: Fundação Casa de Rui Barbosa, 1983. 
RODRIGUES, Rosa Evangelina de Santana Belli. Para um glossário da fala popular Rural paranaense. 2000. Dissertação (Mestrado em Letras) Universidade Estadual de Londrina, Londrina.

SILVA NETO, Serafim da. Introdução ao estudo da lingua portuguesa no Brasil. 5. ed. Rio de Janeiro: Presença, 1986.

- Guia para estudos dialetológicos. Belém: Instituto Nacional de Pesquisa da Amazônia, CNPq, 1957.

TARALLO, Fernando (Org.). Fotografias sociolingü̈sticas. Campinas: Pontes, 1989.

. A pesquisa sociolingüistica. 6. ed. São Paulo: Ática, 1999.

VEADO, Rosa Maria Assis. Comportamento lingüistico do dialeto rural. Belo Horizonte: UFMG/PROED, 1982. 